\title{
O quorum legal para a assembléia geral dos acionistas instalar-se e deliberar.
}

Waldemar Ferreira

1. Muito se questiona acerca da possibilidade de, nos estatutos, restringir-se a faculdade de os reformarem os acionistas, em assembléia geral extraordinária, com exigir-se maior quorum que o legal para que ela funcione e delibere.

Veiu a perlênga de ter deixado em branco a lei n. 3.150, de 4 de novembro de 1882, se lhe era dado modificar, ou não, os estatutos. Supriu-lhe a sinaléfa o decr. n. 8.821, de 30 de dezembro de 1882 , que lhe deu regulamento. Atribuindo, em seu art. 63, à assembléia geral poder para resolver todos os negócios, tomar quaisquer deliberações, aprovando e ratificando todos os atos do interêsse da companhia, nas suas faculdades incluiu a de modificar e alterar os estatutos, "salvo cláusula em contrário". Lícito era, dessarte, aos fundadores da sociedade anônima prescrever-lhes a imutabilidade, embora longo o prazo de sua vigência. Ou estabelecerem-na os acionistas, no percurso desta.

Podendo isso, também dado lhes era, por certo, permitir as refórmas estatutárias, mediante dispositivos rigorosos, que sobremodo as restringissem. Variaram, com tal objetivo, os dispositivos estatutários. Alguns, por exemplo, estipularam que aquelas reformas somente seriam válidas se e quando deliberadas por acionistas, que representassem, no minimo, $75 \%$ do capital social. Ou $80 \%$. Equivalia isso a assegurar a supremacia da vontade da minoria. Acionistas que representassem $25 \%$ ou $20 \%$ do capital podiam 
obstá-las, quer votando contra, quer, mesmo, abstendo-se de votar. Meio era êsse por via do qual os organizadores de companhias, assenhoreados de seus orgãos administrativos, nêles permaneceriam a todo transe, mesmo porque não poucas cláusulas estatutárias exigiam quorum muitissimo alto para que as assembléias gerais pudessem instalar-se e deliberar. Requeriam algumas os votos de $65 \%$ ou mais das ações representadas ou do capital social para que nelas se tomasse qualquer deliberação, fossem ordinárias ou extraordinárias, especialmente se destinada a destituir diretores. Era o meio de eternizarem-se nos cargos, mesmo contra a vontade da maioria absoluta, ou seja a de metade, mais um . Invertiam-se os papéis. A minoria predominava, a despeito e contra a vontade majoritária.

Isso, dum lado. De outro, e pelo que dispunha o art. 141 do decr. n. 434, de 4 de julho de 1891, os estatutos determinariam a ordem que se deveria guardar nas assembléias gerais. Ademais, o número minimo de ações que seriam necessárias para que os acionistas fossem admitidos a coparticipar dos seus trabalhos e a votar. Mas não somente isso. Também poderiam prescrever o número de votos, que a cada acionista competiria, proporciosalmente ao número de ações, que possuisse. Muitos acionistas, dessarte, se privariam do direito de voto porque não tivessem tantas ações que lho assegurassem. Dez, vinte, trinta ou cincoenta ações dariam um voto. Com isso, os pequenos acionistas ficariam codilhados. Não valeriam nada. Condenados à inércia, só lhes assistiria a faculdade de deblaterar. Não a de votar.

2. Outro é o regime do decreto-lei n. 2.627, de 26 de setembro de 1940. Varias medidas tomou êle afim de assegurar as prerrogativas da assembléia geral e dos acionistas, individualmente considerados, ainda quando nela reunidos para conhecimento dos negocios sociais. Outorgou êle, com efeito, à assembléia geral poderes para resolver todos os negócios relativos ao objeto da sociedade e para tomar as decisões convenientes à sua defêsa e desenvolvimento de 
suas operações. Isso, no geral. Dotou-a de amplos poderes deliberantes, na ordem administrativa.

Particularizando, outros lhe atribuiu, privativamente. Tais os de nomear e destituir os membros da diretoria, do conselho fiscal ou de qualquer outro orgão acaso criado pelos estatutos. Os de tomar, anualmente, as contas dos diretores, deliberando sobre o balanço, por êles apresentado, ouvido previamente o conselho fiscal. Os de suspender os direitos aos acionistas. Os de alterar ou reformar os estatutos. Os de deliberar sobre o laudo avaliador dos bens trazidos para o capital social, tanto ao constituir-se a sociedade, pelos subscritores, quanto, constituida ela, por acionistas, afim de aumentá-lo. Os de votar quaisquer vantagens em beneficio dos fundadores, acionistas ou terceiros. Os de autorizar as partes beneficiárias. Os de fundir, incorporar, extinguir e liquidar a sociedade, nomeando e destituindo liquidantes, bem como tomar-lhes contas. E, finalmente, os de autorizar a diretoria a confessar a falência social e a propôr concordata dela preventiva ou suspensiva, derrogado, neste particular, o preceito do art. 159 do decr. $n$. 5.746, de 9 de dezembro de 1929, que explicitamente vedava à sociedade anônima a propositura de concordata preventiva.

Como dêsse elênco de atribuições ressalta, ientre os poderes, da assembléia geral privativos, assinalam-se os de nomear e destituir os diretores da sociedade, os membros do conselho fiscal e, principalmente, os de reformar ou alterar os estatutos.

3. Sendo êsses poderes da privativa competência da assembléia geral e, por isso mesmo, indelegaveis e inderrogaveis, discute-se se é legitimo o dispositivo estatutário por força do qual se exijam condições tais de quorum e de maioria deliberante, que, praticamente, se destitúa aquêle orgão de sua competência, pela impossibilidade de os exercitar.

Prevaleceu, quanto ao quorum, até pouco tempo, a doutrina de J. X. Carvalho de Mendonça, mercê da qual "nos 
estatutos póde-se tornar mais rigorosa a exigência do quorum legal; não é permitido, porém, reduzir as proporções acima mencionadas" (1). Prevaleceu ela incontraditada, primeiro, pela autoridade do grande comercialista; depois, pelos argumentos já aduzidos em tôrno do art. 141 do decr. n. 434, de 4 de julho de 1891.

Incompadece-se ela com o art. 90 do decreto-lei n. 2.627, de 26 de setembro de 1940, de preciso e inconfundivel conteúdo. Ressalvadas, nêle está escrito, "ressalvadas as exceções previstas na lei, a assembléia geral instala-se, em primeira convocação, com a presença de acionistas que representem no minimo um quarto do capital social, com direito de voto. Em segunda convocação, instalar-se-á com qualquer número". Nada mais positivo. Nem mais categorico. Assim prescreveu o decreto-lei no capítulo da assembléia geral ie na secção das disposições gerais.

Reclama o texto considerações a proposito da ressalva e dos acionistas com direito de voto, o que indica a existência de outros sem êsse direito.

4. A ressalva, atinente ao quorum especial, depara-se concretizada, desde logo, no art. 104, da secção relativa à assembléia geral extraordinária, subepigrafada - refórma dos estatutos. A que, expresso é o texto, tenha por objeto reformá-los, "somente se instalará, em primeira ou em segunda convocação, com a presença de acionistas que representém dois terços, no mínimo, do capital, com direito de voto, instalando-se, todavia, em terceira, com qualquer número".

Deduz-se, antes de mais nada,

a) que a assembléia ordinária, ou a extraordinária, cujo objetivo não consista em refórma estatutária, se instala, em primeira convocação, com a presença de acionistas, que representem, no mínimo, um quarto do capital, com direito de voto, e, em segunda, com qualquer número;

(1) J. X. Carvalho de Mendonga. Tratado de Direito Comercial Brasileiro, vol. IV (Rio de Janeiro, 1915), $4 .^{\mathrm{a}}$ ed., pag. $17, \mathrm{n} .^{\circ} 1.136$. 
b) que a assembléia extraordinária, para a refórma dos estatutos, se instala, em primeira convocação, com a presença de acionistas que representem dois terços, no mínimo, do capital, com direito de voto; em segunda convocação, com igual quorum; e, em terceira, com qualquer número.

Nesta hipótese, ha terceira convocação, na anterior dispensada.

Não se depara, em qualquer delas, ensejo para quorum diverso do legal. Basta, em verdade, seja êle o legal para a impossibilidade de derrogar-se pelos estatutos. A lei, segundo velho cânone de direito, só por outra lei se derroga, ou revóga. Sempre, pois, que acionistas, devidamente convocados, se reunam, representando um quarto do capital com direito de voto, no mínimo, ou dois terços, quando de reforma estatutária se trate, existe o quorum legal. Está a assembléia em condições de instalar-se, compondo sua mêsa diretora e entrando na matéria da ordem do dia, ainda que os estatutos digam o contrário. Os que exigissem quorum mais elevado se reputariam, e reputam-se, nêste particular, inânes, diante do texto legal, que sobre êles prevalece. Trata-se, realmente, de matéria de ordem pública. Cuida-se, principalmente, de equilibrar o direito dos acionistas. A presença de um quarto de capital, na primeira hipótese, a do art. 90; e a de dois terços, na segunda, a do art. $104-$ importa na constituição da assembléia geral.

Não se invoquem ensinamentos ministrados no regime da lei anterior ou de leis estrangeiras, que hajam deixado aos estatutos a disciplina das assembléias gerais. A lei atual é regulamentária, nêste particular. Editou regras seguras e insubstituiveis, de relevância imensa.

Impossivel é contrapôr-se ao quorum legal, como bem se percebe, o quorum estatutário. Tem-se êste como inexistente, mercê de sua nulidade, de pleno direito, quando àquêle se sobreponha.

Nullum quod est, nihil est.

O preceito legal, nêste ponto, é insubstituível. Sobre a vontade dos fazedores dos estatutos, prevalece a dos elabo- 
radores da lei. Nem se diga, em contrário, ser a de sociedades anônimas dispositiva. Porque ela é nitidamente regulamentária. Muito pouco deixou para o âmbito estatutário.

5. Caso especial é o da assembléia geral dos acionistas, destinada a deliberar sobre empréstimo mediante emissão de debênturas. Pelo dispositivo do art. 1 , 5 , do decr. $n$. 177-A, de 15 de setembro de 1893, elas não se podem emitir sem prévia deliberação daquela, adotada por tantos acionistas quantos representem, pelo menos, metade do capital social, em reunião a que assistam acionistas em número correspondente a três quartos dêle, pelo menos.

Este é, pois, o quorum legal, tanto para instalar-se a assembléia geral, quanto para que possa ela validamente deliberar (2).

6. Argumenta-se, para sustentar a tése em contrário, não consentir a lei que se instale e funcione assembléia geral a que não acorram acionistas representando menor número de ações que o mínimo por ela exigido. Mínimo menor, sustenta-se, efetivamente não admite ela que os estatutos prefixem; mas não aludiu ao mínimo maior, de molde a poderem eles estabelecer quorum mais elevado.

Carecem de fomento de legalidade argumentos dêsse e outro jaez. Porque a lei é terminante e categórica. A assembléia, em face dela, instala-se, em primeira convocação, com a presença de acionistas que representem, no mínimo, um quarto do capital, com direito de voto; e, em segunda, com qualquer número. Não ha fugir ao imperativo do preceito. Muito menos ao de que ela, para reforma dos estatutos, somente se instala, em primeira ou em segunda convocação, com a presença de acionistas que representem dois terços, no mínimo, do capital com direito de voto; ou, em terceira, com qualquer número.

Não comportam os textos interpretações diversas, mercê da incisiva segurança de seus enunciados.

(2) Waldemar Ferreira, Tratado das Debênturas, vol. 1 (São Paulo, 1944), pag. 72, n. 47. 
7. O capital, sobre cujo montante se computa o quorum, é o com direito de voto. Existe capital sem direito a êste: é o formado pelas ações preferenciais. Os subscritores destas, como prescreve o art. $9, \S$ único, do decreto-lei n. 2.627, de 26 de setembro de 1940, podem ser destituidos do direito de voto; mas a emissão de ações dessa categoria não póde ultrapassar à metade do capital da companhia.

Os estatutos, em verdade, di-lo o art. 81 , podem deixar de conferir às ações preferenciais algum ou alguns dos direitos reconhecidos às ações comuns, inclusíve o de voto, ou conferí-los com restrições, observado o disposto no art. 78, isto é, contanto que não privem seus proprietários ou portadores do direito:

a) de participar dos lucros sociais, observada a regra da igualdade de tratamento para todos os acionistas da mesma categoria;

b) de participar, nas mesmas condições, do acervo social, no caso de liquidar-se a sociedade;

c) de fiscalizar, pela fórma estabelecida na lei, a gestão dos negócios sociais;

d) de preferência para a subscrição de ações, no caso de aumento do capital;

e) de retirar-se da sociedade, nos casos do art. 107, ou de criarem-se ações preferenciais mais favorecidas ou alterarem-se as preferências ou vantagens conferidas às já emitidas. Também no de mudar-se o objeto essencial da sociedade. Ou no de incorporá-la a outra ou com outra fundi-la para organizar-se nova sociedade. Bem como no de cessar-se o estado de liquidação, em que ela se encontre, afim de repô-la em sua vida normal.

Nêste caso, deve o acionista dissidente reclamar e exigir sua retirada, dentro em trinta dias, contados da publicação da ata da assembléia geral, mediante o reembolso do valor de suas ações - o resultado do ativo líquido da sociedade, constante do último balanço aprovado pela assembléia geral, pelo número de ações em circulação. 
Os meios, processos ou ações, que a lei dá ao acionista para assegurar os seus direitos, não podem ser elididos pelos estatutos.

As ações preferenciais, todavia, adquirem o direito de voto, de que não gozem em virtude dos estatutos, quando, pelo prazo nêles fixado, nunca superior a três anos, deixem de ser pagos os respectivos dividendos fixos. Esse direito atribuem elas a seus titulares até ao pagamento, se não cumulativos, ou até que se paguem os cumulativos em atrazo.

O montante das ações sem voto não entra no cálculo do quorum, a menos que elas se encontrem no periodo em que a lei lhes outorga aquêle direito.

\section{II}

8. Não destôa desta ordem de considerações o critério computistico da maioria deliberante nas assembléias gerais dos acionistas.

Erigiu o art. 94 do decreto-lei n. 2.627, de 26 de setembro de 1940, regra de consideravel importância. "As deliberações", nêle se dispôs, "as deliberações da assembléia geral, ressalvadas as exceções previstas na lei, são tomadas por maioria absoluta de votos, não se computando os votos em branco".

Há, pois, necessidade de examinar cada caso, isoladamente. Tal seja a matéria sobre que se delibere, cumpre verificar se, na lei, se determina, para que ela se repute aprovada, maioria qualificada ou diferente da legal - a absoluta de votos, ou metade mais um. Inexistindo exceção, aplica-se a regra geral.

Assim,

a) tratando-se dos casos previstos no art. 105, é necessário que se aprovem por acionistas que representem metade, no mínimo, do capital com direito de voto. Para criar ações preferenciais ou alterar as preferencias ou vantagens de uma ou mais classes, bem assim novas ações mais favorecidas. Ou partes beneficiárias. Ou debênturas. Para 
mudar o objeto essencial da sociedade. Para incorporá-la a outra ou com outra fundi-la. Para propor concordata preventiva ou terminativa da falência. Para, enfim, fazer cessar o estado de liquidação da sociedade, de molde a repô-la em sua vida normal.

b) tratando-se de lançamento de empréstimo por emissão de debênturas, é essencial que a proposta se aprove, em qualquer hipótese, por acionistas que representem, pelo menos, metade do capital social.

Afóra nêsses e em outros casos - pois para a mudança da nacionalidade brasileira da companhia é indispensavel o consentimento unânime dos acionistas, nos termos do art. 72 do decreto-lei n. 2.627, de 26 de setembro de 1940 - a maioria deliberante é a absoluta de votos, não computados os em branco. Pouco importa a matéria da ordem do dia. Póde consistir, mesmo, na destituição dos diretores.

9. Exceções, admite a lei apenas as por ela previstas: "ressalvadas as exceções previstas na lei". Excluiu, portanto, as previstas nos estatutos. Desprezou-as, havendo-as por nenhumas. Aquêles, nêste capítulo, são letras mortas: os seus dispositivos, contrários aos legais, reputam-se não escritos. Inexistem, sob o ponto de vista jurídico, mercê de sua absoluta nulidade.

Abafando dúvidas, o art. 104, referente à assembléia geral extraordinária reformadora dos estatutos, insistiu no afirmar que "as deliberações serão tomadas de conformidade com a regra do art. 94", salvo para as matérias, já mencionadas, que êle entrou a debulhar. Não deixou brécha para as incursões estatutárias.

Os preceitos legais são inderrogaveis pelos estatutos.

10. Têm ingresso nas assembléias gerais os acionistas sem direito de voto. São os acionistas preferenciais. Podem êles, como prescreve o $\S$ único do art. 90, comparecer e discutir a matéria submetida a debate. Discutir é uma coisa. Votar é outra. Coparticipam êles, querendo, das 
discussões. Mas não votam. Porque não votam, as suas ações, como as dos demais, em condições idênticas, não entram no cômputo majoritário.

A cada ação comum ou ordinária corresponde um voto. Os votos de cada pessôa presente são tantos quantas as ações ordinárias, de que seja titular ou portador. Cada uma deve provar sua qualidade de acionista, exibindo os titulares de ações nominativas, se exigido, documento hábil de sua identidade; e os de ações ao portador os respectivos títulos ou documentos, que provem terem sido êstes depositados na séde e escritório social ou em estabelecimento, bancário em regra, designado nos anúncios convocatórios, confórme determinarem os estatutos. Nada se opõe a que os acionistas se representem por procuradores, que tambem sejam acionistas, vedado o exercicio do mandato aos membros da diretoria, do conselho fiscal ou de outro orgão acaso criado pelos estatutos. Têm qualidade para também comparecer os representantes legais dos acionistas.

\section{III}

11. Artigos de estatutos, modificativos do quorum para que se instale a assembléia geral, ou elevando assaz o critério do cálculo da maioria nas votações, que nela se realizem, destinam-se, inequivocamente, a impedir as infiltrações minoritárias. Se os administradores da companhia dispõem de dois terços das ações e, pois, dos votos correspondentes, o exigirem êles, através dos estatutos, que a maioria seja sempre, e em todos os casos, a de dois terços, é para que possam evitar surprêsas, que lhes sejam desagradaveis. Tornam-se as sociedades anônimas fechadas, dessarte, impedida a entrada de estranhos, pela impossibilidade, em que se encontrem, de constituir, pelo aglutinamento de outros acionistas, maioria deliberante.

Opôs-se o decreto-lei n. 2.627, de 26 de setembro de 1940, a que tal aconteça. 
Prescreveu êle as condições para que as assembléias gerais se instalem, funcionem e deliberem. Mais ainda, cuidou da fórma e prazo de convocá-las, por miúdo. Convoca-se por convite ou anúncio publicado pela imprensa, três vezes, assim no órgão oficial da União ou do Estado, conforme o local em que esteja situada a séde social, como em outro jornal de circulação grande, mencionando-se, ainda que sumariamente, a ordem do dia, ademais do local, do dia e da hora. O local é o em que se sitúe a séde da sociedade. Quando seja outro, deve mencionar-se com clareza; mas, em caso algum, em localidade outra que não a em que aquela séde se encontre.

Entre o dia da primeira publicação do anúncio convocatório e o em que a assembléia deva funcionar ha que mediar o prazo mínimo de oito dias, para a primeira convocação, e de cinco, para as convocações posteriores.

12. Pertence a iniciativa do convite à diretoria, nos casos previstos em lei ou nos estatutos. Não quer isso dizer seja indispensavel que o assinem todos os diretores. Basta que a diretoria delibére. Cumpre ao diretor-presidente, ou ao incumbido de executar-lhe as deliberações, torná-las efetivas. Devolve-se aquela iniciativa, entretanto, ao conselho fiscal, quando a diretoria retarde, por mais de um mês, o da assembléia gerảl ordinaria, a realizar-se nos quatro mêses subsequentes ao termo do exercicio financeiro social, coincidente, na generalidade dos casos, com o ano solar. Além disso, cabe-lhe convocá-la extraordinariamente, quando ocorram motivos graves e urgentes. Igual faculdade compete ao acionista, quando retardada a assembléia ordinária por mais de dois mêses, sem que o conselho fiscal a haja convocado; ou, extraordinariamente, quando representem os convocantes mais de um quinto do capital social com direito de voto ie a diretoria se abstenha de convocá-la, no prazo de oito dias, contados da data do requerimento, devidamente fundamentado, em que a solicitem. 